\title{
Personalization of Learning Objects through Knowledge Management Process
}

\author{
J. L. Melgar-Garcia, M. Sanchez-Brito, C. F. Garcia-Hernandez \\ National Institute of Electricity and Clean Energies, Cuernavaca, Morelos, \\ Mexico \\ \{jlmelgar, miguel.sanchez, cfgarcia $\} @$ ineel.mx, www.ineel.mx
}

\begin{abstract}
The correct average of the knowledge has been getting more attention for companies in nowadays because the competitive advantages, if there is rotation of workers. The use of employee's experiences in addition to the literature contained in books or reviewed on the internet allows the development of personalized and reusable learning objects useful in a specific topic. The knowledge management process, professional team necessary to recover and process experiences from experts and an example of tools to produce and distribute the learning objects are also provided in this research.
\end{abstract}

Keywords: learning object, SCORM, LMS, knowledge management process.

\section{Introduction}

An increasing number of companies have been destining resources to catch the knowledge acquired by their employees with different purposes, two of the most important are: hold back the experiences of employees near to the retirement and help in the self-training process. In both cases, develop learning objects (LO) which contain not only information about books or papers, but also the specific experiences recovered by people who has been developing that activity is essential to get useful learning objects. To achieve LO with that specific characteristic, a multidisciplinary team is required. It is possible separate the team according to their particular objectives on the project, on these research two parts are proposed: "process team" and "software team". In resume, the first one is responsible of recover information about the theme to develop, the second one, must represent that information recovered through interactive activities to stimulate the learning process. Because different ways to learn, the incorporation of a pedagogue on software team is proposed. On the following section, the knowledge management process is described.

\section{Related Work}

In [1] authors explain in detail the sequencing of learning objects on LMS based on SCORM standard using cmi element and JavaScript, being learning objects containing 
teaching materials, following the guidelines proposed by ADL. In [2] authors explain an application of pedagogical tools to an on-line course for e-learning, including an example of a course specification showing an activity, an example of a script for an activity, and a course development model. In this research work, a knowledge management process is presented.

\section{LO Construction}

The success of the LO will depend of how much it brings to the learning process and the interactivity which it was developed [3]. To produce useful LO is really important complement the information obtained by the literature with the tacit knowledge earned by experts through the time invested developing a certain activity.

\subsection{Process Team Interaction}

Currently, many techniques to translate the tacit knowledge to implicit have been exposed, however, this research consider a set of direct interviews between an expert and the process team as the best way to achieve that objective. The number of meets will depend on the theme length and it complexity; usage of a video camera is proposed to review agreements or at least notes about the meets must be developed by the process team. Once completed the interviews, process team should to share their video records or notes, with the software team to transform them on interactive activities [4].

\subsection{Software Team Interaction}

Together with a member of process team and with the pedagogue, the software team translate notes or video records in learning objects through use of an authoring tool and many design tools such as Flash of Adobe. The usage of an authoring tool makes easier the LO production because software team does not require language programming capabilities, the authoring tool add automatically the elements required to communicate the user interactions on the LO and the platform that reproduce the LO, usually a Learning Management System (LMS) [5]. To set a minimum of interactions (among others measures) the SCORM (Sharable Content Object Reference Model) standard was published. Both platform and LO are involved by SCORM [6, 7], that makes easier get a measure of the user average, however, by the same standard the navigation (principally) is affected, allowing only a sequential review of the $\mathrm{LO}$ and giving to the user the capability of review all the themes contained on the LO without any restriction which is a problem in case of an exam (for example). On the following section, the development of personal knowledge paths is explained.

\subsubsection{Developing Personal Learning Paths through LO}

As was mentioned before, SCORM standard includes both LO and LMS. To get a measure about the interactions of users on the LO, SCORM propose a set of tracking 
elements called "cmi elements". The use of cmi elements allows to the software team get measures about many aspects during user interaction such as time spend on a specific activity or even in a slide, correct answers on a test, the last slide visited, etc. SCORM propose more than 20 different cmi elements, which could be used to develop rules and achieve a specific learning path for the users. However, according to SCORM rules, any activity on a LO must be related with other, so, to link them, a JavaScript function is used.

The user name is stored on LMS on cmi.core.student_name. To verify the function, the Fig. 1 is displayed, these figure contain a print screen about a LO contained in a LMS.

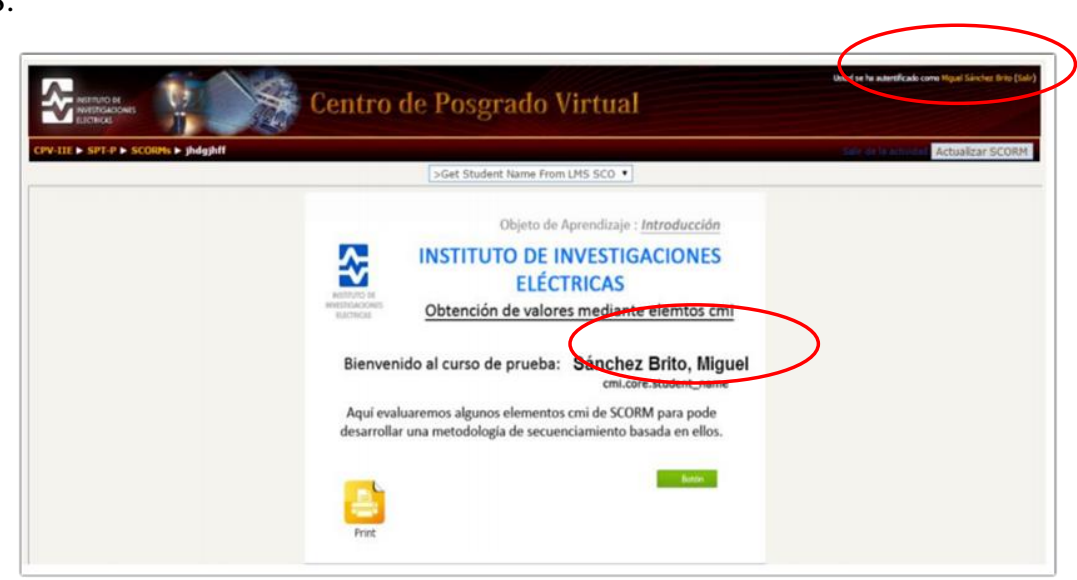

Fig. 1. CMI element evaluation.

To get for example, the qualification obtained in a test, the "cmi.core.score.raw ()" must be employed. Once finished the LO and their rules of behaviour based on user interactions, software team proceeds to publish the LO. Publish is the process by which

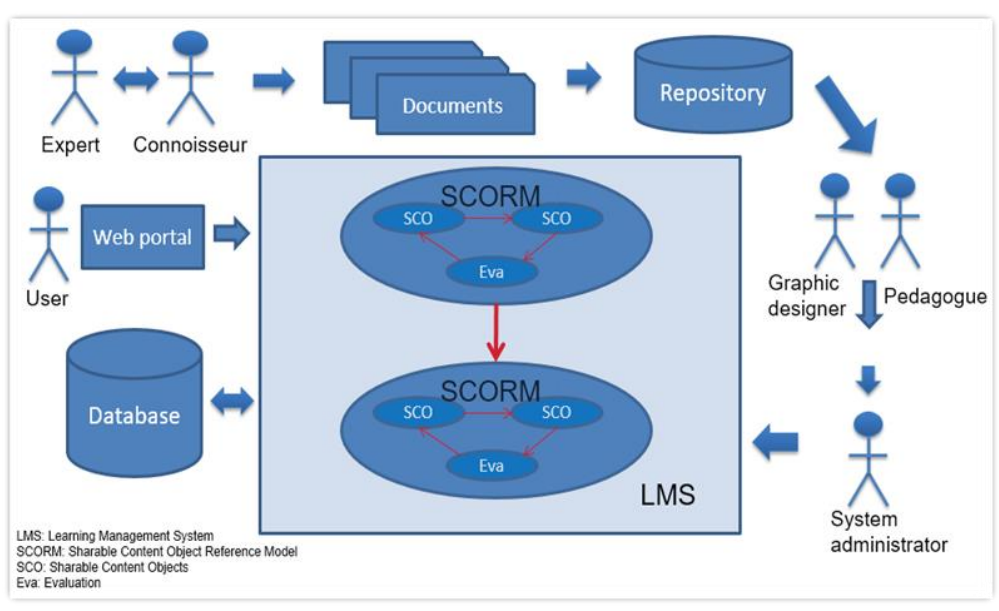

Fig. 2. LO creation process. 
the authoring tool add automatically the code required to enable communication between the LO and the LMS. The publish result is a ".zip" file which software team must upload to the LMS. In Fig. 2, the process and the necessary team is presented.

\subsubsection{Program Code}

The code allows ask to the LMS for the user name to use it in a specific activity. JavaScript code to get cmi elements from LMS are listed.
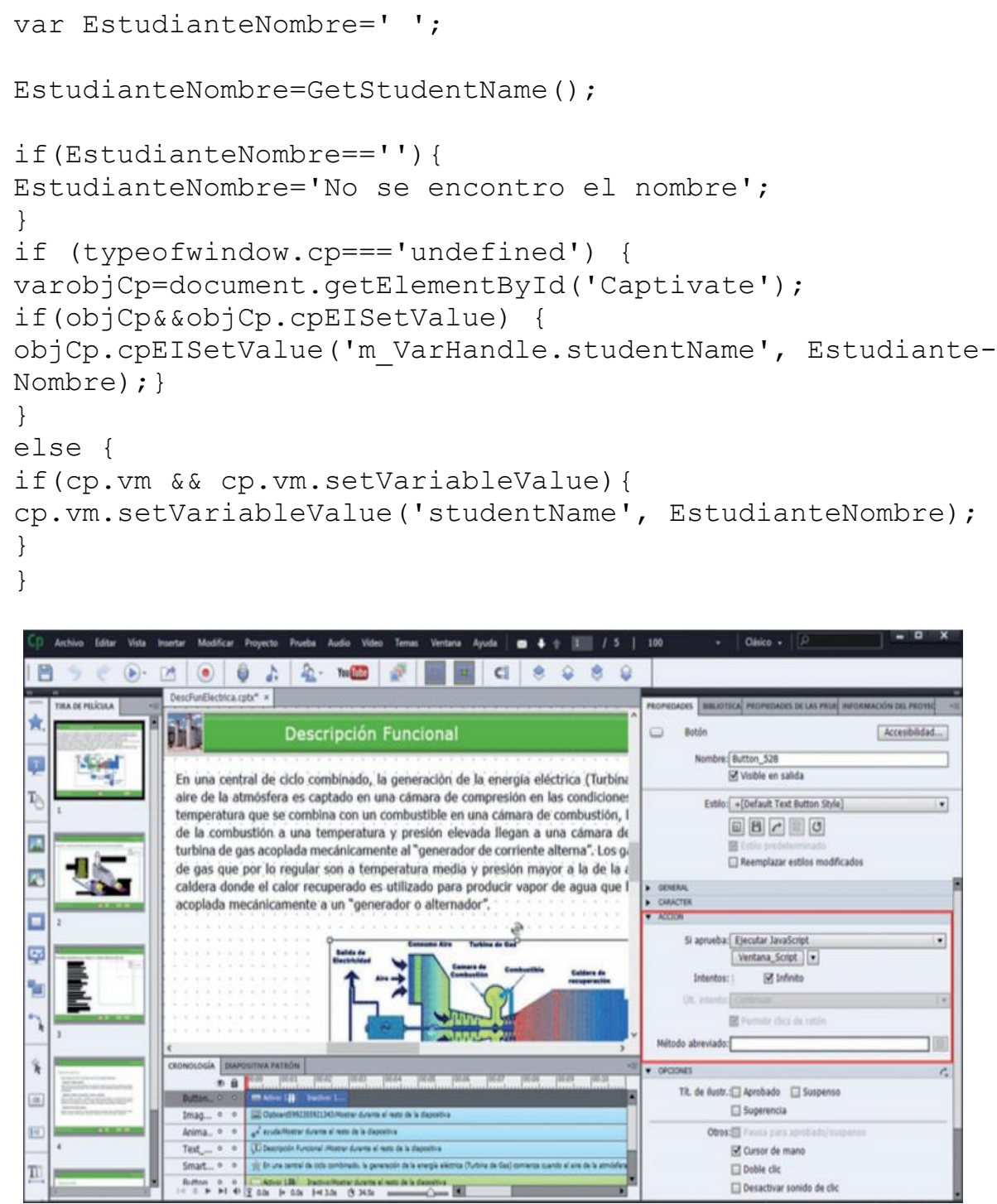

Fig. 3. Captivate interface. 


\section{Application of the Process}

Following the proposed process with team specified a set of LO related to energetic field was developed. Together with the process and software team, a group of five experts were involved. The process team was integrated by three engineers (closely related to energetic field), the software team conformed by two graphic designers and 3 software engineers was required to develop an interactive LO conformed by 126 topics encompassed on themes such as: "Principal Generation System", "Auxiliary Service System", "Measure, Control and Protection System" and "Principal Transformation System".

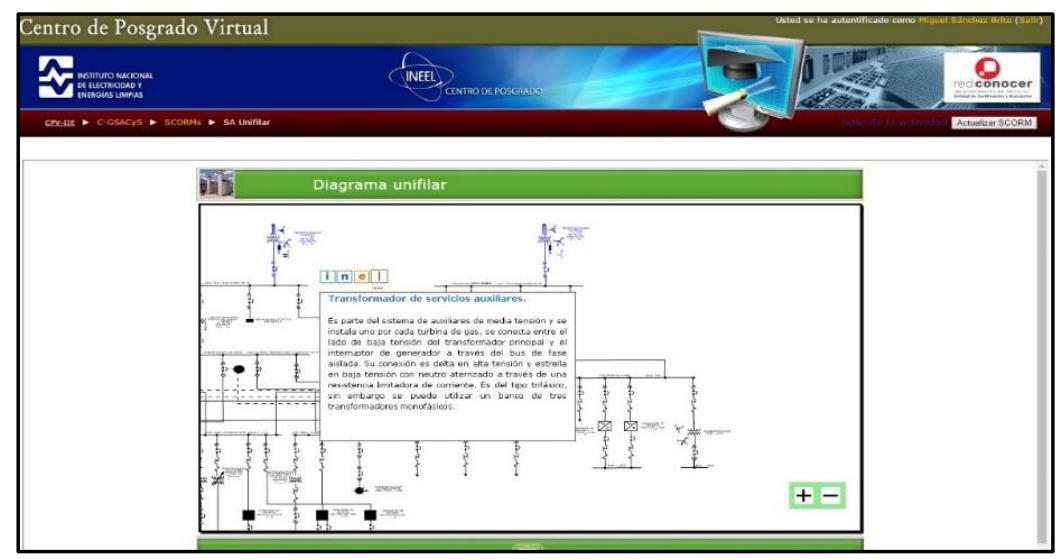

Fig. 4. Sample of the Developed Learning Object.

To produce the LO the authoring tool "Captivate" from the suite of e-Learning tools of Adobe in addition with design tools such as Photoshop and Illustrator and Flash to create interactive activities were used. In Fig. 3, a print screen of Captivate interface is presented.

The functionality of the LO was evaluated on a LMS Moodle platform where the Postgraduate Virtual Center of National Electricity and Clean Energy Institute is placed. In Fig. 4, a topic developed by the LO uploaded to the LMS Platform is showed. On this particular case, many interactions must be developed: a zoom function to visualize in detail the diagram, a brief description of the element selected from the diagram activate through click actions, 3 different buttons linked to different fields of a database, buttons allow to see: standards applied for the selected element (n), a long description of the element (i), specifications applied for the element (e) and a list to daily verification of the element on the real workday.

\section{Conclusion}

The correct average of the knowledge has been getting more attention for companies in nowadays because the competitive advantages. The use of employee's experiences in 
addition to the literature contained in books or reviewed on the internet allows the development of personalized and useful learning objects in a specific topic. In conclusion, the knowledge management process, professional team necessary to recover and process experiences from experts and an example of tools to produce and distribute the learning objects are also provided in this research work.

\section{Future Work}

The use of Flash tool to develop interactions on activities, inhibit the possibility to access the LO through mobile device, because of that a new methodology using a different tool or even develop the interactions through a programming language must be applied.

\section{References}

1. Sanchez-Brito, M., García-Hernández, C.F., Ruiz-Ascencio, J.: Secuenciamiento de objetos de aprendizaje basados en SCORM mediante elementos CMI y JavaScript. En: Congreso Internacional sobre Innovación y Desarrollo Tecnológico, CIINDET (2016)

2. Anbar, A.A., Al-Shishtawy, A.M., Al-Shandawely, M., Mostafa, T.A., Hammad, A., Sunoallah, S., Everett, J., Özgüven, K.: Applying Pedagogical Concepts in Online Course Development. In: Experiences from the Mediterranean Virtual University, pp. 111 (2005)

3. Advanced Distributed Learning Network (2016), http://www.adlnet.org

4. FAO Fiat Panis: Metodologías de E-learning. FAO (2014)

5. Moodle (2016), http://www.moodle.org

6. Rustici Software (2016), http://www.scorm.com

7. UNESCO: La Educación y las TIC (2016), http://www.unesco.org/es/higher-education/ higher-education-and-icts/ 